\title{
Análise das informações por segmento: divulgação de informações gerenciais pelas empresas brasileiras
}

\section{Analysis of segmental information: disclosure of management information by brazilian companies}

\section{Humberto Silva Aillón}

Mestrando em Controladoria e Contabilidade pela Universidade de São Paulo Endereço: Avenida Prof. Luciano Gualberto, no 908, FEA 3 - Cidade Universitária CEP: 05508-900 - São Paulo/SP - Brasil

E-mail: humberto.aillon@gmail.com

Telefone: (11) 9.9271-6482

\section{Júlio Orestes da Silva}

Doutorando em Controladoria e Contabilidade pela Universidade de São Paulo Endereço: Avenida Prof. Luciano Gualberto, no 908, FEA 3 - Cidade Universitária CEP: 05508-900 - São Paulo/SP - Brasil

E-mail: orestesj@gmail.com

Telefone: (11) 9.8893-8830

\section{Anderson Ferreira Pinzan}

Mestrando em Controladoria e Contabilidade pela Universidade de São Paulo Endereço: Avenida Prof. Luciano Gualberto, no 908, FEA 3 - Cidade Universitária CEP: 05508-900 - São Paulo/SP - Brasil

E-mail: andersonpinzan@aol.com

Telefone: (11) 9.9686-0074

\section{Artur Filipe Ewald Wuerges}

Doutorando em Administração pela Universidade Federal de Santa Catarina

Endereço: Universidade Federal de Santa Catarina - Centro Sócio-Econômico - Núcleo de Estudos em Contabilidade e Controladoria - Campus Universitário

CEP: 88040-500 - Florianópolis/SP - Brasil

E-mail: awuerges@gmail.com

Telefone: (48) 9151-3713

Artigo recebido em 27/10/2011. Revisado por pares em 13/11/2012. Reformulado em 28/12/2012. Recomendado para publicação em 06/02/2013 por Sandra Rolim Ensslin (Editora Científica). Publicado em 30/04/2013. 


\title{
Resumo
}

O cenário de convergência contábil internacional conduz as organizações brasileiras à nova realidade de desafio informacional, à divulgação de informações gerenciais, como, por exemplo, informações por segmento. O objetivo deste trabalho consiste em verificar como são evidenciadas as informações gerenciais publicadas na nota explicativa de informações por segmento nas empresas que compõem o IBrX-50. Nos achados, conclui-se que (i) a evidenciação é distinta entre os setores; e (ii) existe um baixo nível de disclosure das informações gerenciais. Esses fatores podem ser um indício da tentativa de ocultar a ineficiência de gestores, ou a supressão de informações como barreira informacional para novos competidores.

Palavras-chave: Segmentos Operacionais. Evidenciação. Contabilidade Gerencial. Normas Contábeis Internacionais.

\begin{abstract}
The scenario of international accounting convergence leads Brazilian organizations to a new reality of informational challenge, the disclosure of management information, for example, the segmental information. The aim of this work is to verify how the management information are disclosure in the note published for segmental information in the companies listed in the IBrX-50. Findings demonstrate (i) the disclosure is different among sectors, (ii) there is a low level of management information disclosure. These variables may be an indicative of an attempt to hide the inefficiency of managers, or deletion of information as informational barrier for new competitors.
\end{abstract}

Keywords: Operating Segments. Disclosure. Management Accounting. International Accounting Standards.

\section{Introdução}

Com a aceleração do processo de globalização, em razão do advento de novas e complexas operações financeiras, massificação dos investimentos internacionais, ascensão do mercado de capitais e as recentes crises financeiras, uma nova realidade econômica obrigou as empresas a aumentar o nível de transparência das suas demonstrações financeiras. A dicotomia entre divulgar ou não o máximo de informações é um ponto crítico que permeia o mundo empresarial, visto que, por diversas vezes, entidades reduzem a quantidade de informação disponível como estratégia contra seus concorrentes, desconsiderando que a divulgação pode ser importante para a redução do custo de capital, o aumento da liquidez das ações e a consolidação da imagem no mercado (SOLOMON; SOLOMON, 2004).

O período entre 1997 e 2002 foi importante para impulsionar a harmonização internacional das normas contábeis, logo após os problemas financeiros enfrentados por empresas como Enron e WorldCom. Diversos questionamentos recaíram sobre a Contabilidade, e se estava de fato cumprindo o seu papel na divulgação da informação útil e 
oportuna para tomada de decisão. Desse modo, a harmonização contábil aparece como uma forma de maximizar a utilidade da informação contábil para todos os usuários (LEMES; CARVALHO, 2004).

Diante da necessidade de harmonização, o Brasil confirmou sua posição a favor do International Accounting Standard Board (IASB), ao adotar a Lei n. 11.638/07, onde se define que as normas expedidas pela Comissão de Valores Mobiliários deverão ser elaboradas em aderência aos padrões internacionais de Contabilidade. No Brasil, elas são responsabilidade do Comitê de Pronunciamentos Contábeis (CPC). Dessa forma, o CPC, órgão responsável pelo estudo à emissão de Pronunciamentos Técnicos sobre procedimentos de Contabilidade, visa à centralização e à uniformização do seu processo de produção. Essa uniformização contribui para garantir o objetivo fundamental da Contabilidade, além de reduzir a assimetria existente entre a Contabilidade Financeira e a Gerencial (FREZATTI et al., 2007; IUDÍCIBUS, 2005).

Semelhante ao processo evolutivo vivido pela Contabilidade, as empresas estão inseridas em um mercado cada vez mais evoluído. Para se diferenciarem, garantindo sua rentabilidade e market-share, diversificam seus produtos e serviços por meio de atuação em um segmento específico de mercado (PORTER, 1985). Cada segmento operacional possui característica única, o IASB publicou a norma IFRS 8 Operating Segments, produto da revisão da norma americana SFAS 131 Disclosure about Segments of an Enterprise and Related Information e da IAS 14 Segment Reporting.

A abordagem básica do pronunciamento técnico IFRS 8 trata da divulgação de informações financeiras conforme a visão da gerência da entidade, corroborando assim na convergência entre a Contabilidade Financeira e a Gerencial. Por sua vez, essa informação ganha caráter estratégico e é muito suscetível a erros, tornando as empresas cautelosas em sua divulgação para não causar impacto negativo para estas (MOURAD, 2009). Nessa linha, cada segmento operacional de uma entidade, além de apresentar riscos e retornos distintos, pode ainda necessitar de investimentos incongruentes. Torna-se imprescindível a divulgação das informações solicitadas no IFRS 8 para que o usuário possa decidir qual é melhor investimento (EPSTEIN; JERMAKOWICZ, 2010).

Gamble e Simms (2010) evidenciam duas insatisfações com as informações de segmentos operacionais, sendo a primeira relacionada à grande flexibilidade dada aos gestores para definição dos segmentos operacionais; e a segunda relaciona-se à necessidade de informação para os investidores elaborarem análises de longo prazo, criticando o desempenho das decisões dos gestores da entidade. Diante do exposto, elabora-se a seguinte questão de pesquisa: Como são evidenciadas as informações gerenciais publicadas na nota explicativa de informações por segmento nas empresas que compõem o IBrX-50?

Nesse sentido, o objetivo deste trabalho é verificar como são evidenciadas as informações gerenciais publicadas na nota explicativa de informações por segmento nas empresas que compõem o IBrX-50. Para atingir o objetivo principal deste estudo busca-se ainda: (i) identificar a evidenciação das informações gerenciais por setores de atuação; (ii) analisar quais informações gerenciais são mais evidenciadas; e, (iii) verificar quais fatores influenciam a divulgação na nota explicativa de informações por segmento.

A pesquisa justifica-se pela relevância das informações financeiras divulgadas pelas empresas, que repercutem nas decisões que afetam o mercado financeiro e de capitais. Contribui ainda por fornecer um diagnóstico das informações gerenciais inseridas nas demonstrações financeiras a partir da adoção das normas internacionais de Contabilidade, 
especificamente IFRS 8. Hansen e Mowen (2005) afirmam que os gestores precisam cada vez mais da informação analítica por segmento operacional para elaborar projeções, além de informações para a tomada de decisão de continuidade operacional e nível de financiamento.

No Brasil, destacam-se pesquisas relacionadas à IFRS 8, dentre elas está a de Boscov (2009) e Mourad (2010), porém ambas apresentam enfoque diferente do estudo proposto.

A estrutura do artigo contempla cinco seções. A contextualização, a problematização, a questão de pesquisa, os objetivos, a justificativa e a estrutura do trabalho estão contempladas na seção 1 . Na seção 2 , encontra-se o referencial teórico da pesquisa com as discussões e evidências de pesquisas anteriores encontradas na literatura, tanto no Brasil quanto no exterior. Na seção 3, apresenta-se a metodologia com a descrição da técnica de análise de conteúdo empregada no estudo. $\mathrm{Na}$ seção 4, são apresentados os dados coletados e a análise das informações. Por fim, a seção 5 contém as considerações finais como resposta ao problema de pesquisa introduzido no estudo.

\section{Referencial Teórico}

\subsection{Informações por segmento}

O IFRS 8 Segmentos Operacionais foi criado em 2006 sucedendo o IAS 14 Relatório por Segmento. Na concepção do $I A S B$, o método que utiliza os relatórios gerenciais é o mais adequado para análises e estudos dos relatórios financeiros e, dessa forma, os usuários da informação contábil tem mais facilidade para entender os riscos e as oportunidades da empresa.

No Brasil, temos o pronunciamento técnico CPC 22, versão traduzida da IFRS 8, e sua relevância está no fato da divulgação de informações que são utilizadas nas decisões cotidianas pelo gestor de operações (aquele cuja função é destinar recursos e avaliar o desempenho dos segmentos operacionais da entidade) ou pelo gestor de segmento (aquele cuja função é reportar ao gestor de operações as atividades e os processos operacionais). Como não é objetivo do presente estudo discutir minuciosamente as imposições da norma, mas, sim, estudar o que efetivamente as empresas estão divulgando, a seguir discute-se a visão macro dos principais itens do IFRS 8. Conforme definido no CPC 22, para uma entidade classificar um componente da empresa como um segmento operacional é necessário que sejam analisadas três situações:

a) se esse componente gera receitas e consequentemente incorre em despesas;

b) se o principal gestor de operações revisa os resultados operacionais por conta da relevância do segmento;

c) se existe informação financeira disponível para divulgação.

Com base no CPC 22, as informações mínimas necessárias na divulgação da entidade são:

a) os fatores utilizados para identificar os segmentos divulgáveis da entidade, incluindo a base da organização (por exemplo, se a administração optou por organizar a entidade em torno das diferenças entre produtos e serviços, áreas geográficas, ambiente regulatório, ou combinação de fatores, e se os segmentos operacionais foram agregados);

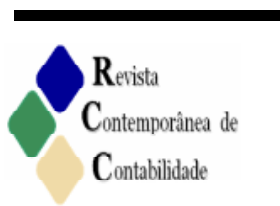


b) tipos de produtos e serviços a partir dos quais cada segmento divulgável obtém suas receitas;

c) informações sobre o lucro ou prejuízo reconhecido dos segmentos, incluindo as receitas e as despesas específicas que compõem o lucro ou o prejuízo desses segmentos;

d) informações sobre os respectivos ativos, os passivos e as bases de mensuração;

e) conciliações das receitas totais dos segmentos, do respectivo lucro ou prejuízo, dos seus ativos e passivos e outros itens materiais com os montantes correspondentes da entidade, sendo que essas diferenças podem incluir as decorrentes das políticas contábeis e das políticas de alocação de passivos utilizados conjuntamente, necessárias para a compreensão da informação por segmentos divulgada;

f) caso a receita de um único cliente externo represente mais de $10 \%$ do total também deve ser evidenciada analiticamente os clientes nesta situação.

Ainda que os parâmetros de definição de segmentos sejam estabelecidos e quais informações devam ser divulgadas no IFRS 8, como a sua elaboração possui certa liberdade, por diversas vezes essa flexibilidade pode causar perda informacional para os investidores, tanto no âmbito de comparação de empresas quanto de segmentos (MOURAD, 2009).

\subsection{Estudos Anteriores: DISCLOSURE da informação por segmento}

O tema informações por segmento é estudado por alguns pesquisadores que, em grande parte, buscam analisar a importância da informação, além de discutir o foco gerencial das demonstrações financeiras. Alguns trabalhos internacionais estão relacionados a IAS $14 \mathrm{e}$ IFRS 8. Destacam-se os mais recentes como Garrod (2005); Birth et al. (2007); Wenchao e Simon (2007); Gamble e Simms (2010); Benjamin et al. (2010); Rahahleh (2010); e Schneider e Scholze (2011). No Brasil, os estudos mais recentes são de Mourad (2009) e Boscov (2009), o que comprova a necessidade de mais estudos voltados para IFRS 8, uma vez que essa norma é uma das responsáveis pela convergência entre a Contabilidade Financeira e a Gerencial.

Em Garrod (2005), foram analisadas as empresas do FTSE 200 (200 ações mais representativas da Bolsa de Londres), e a conclusão do estudo demonstrou que empresas que divulgam relatório por segmentos com alta qualidade informacional são impactadas negativamente (desvantagem competitiva) em comparação com aquelas que divulgam relatórios por segmentos com qualidade inferior. Concluiu-se ainda que as empresas que divulgam seus relatórios por segmento de acordo com a região geográfica e não por linha de atividade também são impactadas negativamente, uma vez que podem divulgar informações comerciais importantes, como oportunidades de penetração no mercado e aumento de marketshare em determinada região geográfica. Schneider e Scholze (2011) também analisaram o impacto da agregação das informações por segmento e concluíram que a agregação das informações, ou seja, a redução da informação divulgada, é superior em determinados mercados, como um entrave à entrada de novos competidores no mercado de atuação.

Semelhante aos estudos de Garrod (2005), Schneider e Scholze (2011), Wenchao e Simon (2007) analisaram a divulgação das informações por segmento das empresas contidas no FTSE 100 (100 ações mais representativas da Bolsa de Londres) com o objetivo de explicar a variação das projeções dos lucros por ação. Os autores concluíram em sua pesquisa que as projeções são melhores quando as empresas divulgam as informações por segmento 
com base na região geográfica, quando divulgam o mercado de atuação e quando a divulgação possui grande comparabilidade com as informações do setor de atuação.

Outro aspecto importante foi evidenciado por $h$ et al. (2004) que verificaram que a divulgação das informações por segmento é relevante para previsão das vendas e dos lucros, e que uma série de fatores como competitividade e comparação das informações, divulgados pelos concorrentes, impactam o nível de divulgação.

Embora as pesquisas discutidas anteriormente demonstrem benefícios das informações por segmento, Gamble e Simms (2010) elaboraram um novo modelo para a divulgação das informações por segmento com base no Custeio ABC (Activity Based Costing), descrevendo uma lista de informações necessárias na divulgação de IFRS 8, com a utilidade da metodologia de Custeio $\mathrm{ABC}$ para a alocação dos resultados por segmento, visando à ampliação e facilidade aos investidores no que tange à análise das perspectivas gerenciais divulgadas.

Pela análise da qualidade das informações por segmento divulgadas em algumas empresas na Malásia, Benjamin et al. (2010) concluíram que as informações divulgadas são de baixa qualidade e que, com a adoção da IFRS 8 , existe a expectativa de melhora na qualidade da informação.

Já Rahahleh (2010) analisou as dificuldades e o grau de implementação da IFRS 8 nas empresas situadas na Jordânia e elaborou propostas para reduzir as dificuldades das empresas e assim aumentar o nível de implementação da norma.

No contexto brasileiro, a divulgação de informações por segmento, IFRS 8 , não é alvo de estudos específicos. Uma pesquisa recente desenvolvida por Mourad (2009) verificou com uma amostra do FTSE 100 e por setor como as empresas listadas determinam a segmentação primária, e se estas eram como área de negócios ou como área geográfica. Os achados demonstraram que as empresas do FTSE 100 apresentam propensão ao reporte utilizando a linha de negócios como segmento primário, e área geográfica como segmento secundário.

Por meio de questionário enviado a profissionais com conhecimento em IFRS, do Brasil e da Europa para análise da opinião sobre os relatórios por segmento, Mourad (2009) concluiu que as empresas possuem propensão a ocultar informações por medo dos concorrentes e, como confirmação empírica, $72 \%$ dos profissionais acreditam que as empresas ocultam informações estratégicas nos relatórios.

No Brasil, Boscov (2009), ao entrevistar preparadores, auditores, analistas de demonstrações financeiras e acadêmicos, verificou o efeito da vinculação da Contabilidade Financeira à Contabilidade Gerencial na qualidade das informações financeiras e no nível de disclosure. Observou que não existiu concentração unânime nas respostas, ou seja, dentre as perguntas realizadas, alguns entrevistados responderam que terá uma redução no nível de disclosure; porém, em contrapartida, outros entrevistados responderam que a quantia das informações apresentará aumento gradativo.

A dificuldade na obtenção de informações por segmento é compartilhada pelas informações ambientais, pois, conforme resultado apresentado por Rodrigues, Machado e Cruz (2011), as empresas objeto de estudo não evidenciam os custos ambientais por natureza de ativo. Dessa forma, os autores reforçam a importância da exigência pela lei da evidenciação dessas informações, e também de cobrança por parte da sociedade e de investidores de mais transparência nas informações divulgadas.

Com base nas pesquisas anteriores realizadas, é legitimada a relevância deste estudo, uma vez que o levantamento de dados com a radiografia das informações por segmento não 
foi realizada após a adoção das IFRS pelas empresas brasileiras, demonstrando um importante espaço para estudos que busquem verificar as informações por segmento após a adoção das normas internacionais de Contabilidade.

\section{Metodologia de Pesquisa}

O presente estudo foi conduzido de maneira descritiva, utilizando informações disponíveis nas empresas que compõem o Índice IBrX-50. A amostra correspondeu às empresas integrantes do Índice IBrX-50, que mede o retorno total de uma carteira teórica composta por 50 ações selecionadas entre as mais negociadas na BMF\&BOVESPA em termos de liquidez, ponderadas na carteira pelo valor de mercado das ações disponíveis à negociação. A escolha pelas empresas que compõem o IBrX-50 deve-se à relevância da carteira no ambiente de negociação da Bolsa de Valores brasileira.

A pesquisa compreendeu o ano de 2010, cujas informações foram coletadas no site da CVM, e, agrupadas, totalizaram uma amostra de 48 empresas com atuação no Brasil. As informações foram analisadas e explicitadas por meio de coleta de dados de caráter documental com base nas notas explicativas das empresas. As informações foram analisadas por meio das abordagens qualitativa e quantitativa, baseando-se na técnica de Análise de Conteúdo. Posteriormente utilizou-se o Modelo de Regressão Múltipla para testar variáveis explicativas que impactam o nível de evidenciação da nota explicativa.

$\mathrm{Na}$ técnica de análise de conteúdo, os dados são obtidos por meio das evidenciações e interpretações do conteúdo (MARTINS, 2002). Após a obtenção, os dados são quantificados, passíveis da análise por métodos quantitativos. Kolbe e Burnett (1991, p. 245) asseveram que a utilização da técnica de análise de conteúdo deve ser conduzida por meios objetivos e confiáveis.

$\mathrm{Na}$ acepção de Bardin (1977), a Análise de Conteúdo consiste na análise de comunicação, utilizando procedimentos sistemáticos e objetivos de descrição de conteúdo que permita a inferência de conhecimentos. Ainda de acordo com Bardin (1977), o conjunto de documentos analisados é nomeado de corpus. Conforme denota Freitas e Janissek-Muniz (2000), a parte vital da Análise de Conteúdo consiste nas categorias definidas por estes como rubricas significativas, em função das quais o conteúdo será classificado e eventualmente quantificado. Os autores asseveram ainda que as categorias se originem dos documentos objetos da análise.

A pesquisa bibliográfica serviu de suporte para a revisão das pesquisas anteriores e, conforme Martins e Theóphilo (2007), esse tipo de pesquisa procura explicar e discutir um assunto com base em referências publicadas em jornais, sites etc.

Concomitantemente, o estudo descritivo foi realizado com base em pesquisa documental, empregada na fonte primária, ou seja, fontes que não foram editadas previamente, mas, sim, materiais compilados pelo autor.

\subsection{Quesitos para Análise de Conteúdo}

O Quadro 1 apresenta as categorias que serviram de base para a Análise de Conteúdo. Os estudos que serviram de suporte à construção da métrica foram realizados por Niyama et 
al. (2010) e Borba et al. (2009). Complementarmente, o pronunciamento técnico CPC 22 foi utilizado como suporte para a construção das categorias.

Quadro 1 - Estratégias de análise da evidenciação das informações por segmento

\begin{tabular}{|c|l|}
\hline Categoria & CPC 22 \\
\hline 1 & Evidenciou o motivo da não publicação \\
\hline 2 & Evidenciou quem é o gestor principal da operação \\
\hline 3 & Evidenciou a composição do segmento operacional \\
\hline 4 & Evidenciou se foi adotado como unidade de negócio ou região geográfica \\
\hline 5 & Evidenciou a quantidade de segmentos operacionais \\
\hline 6 & Evidenciou o método de agregação de segmentos \\
\hline 7 & Evidenciou base comparativa \\
\hline 8 & Evidenciou Receitas por segmento \\
\hline 9 & Evidenciou Custos por segmento \\
\hline 10 & Evidenciou Despesas por segmento \\
\hline 11 & Evidenciou Resultado Operacional por segmento \\
\hline 12 & Evidenciou Lucro/ Prejuízo do Exercício por segmento \\
\hline 13 & Evidenciou Ebitda por segmento \\
\hline 14 & Evidenciou Ativos por segmento \\
\hline 15 & Evidenciou Passivos por segmento \\
\hline 16 & Evidenciou o montante de investimentos por segmento \\
\hline 17 & Evidenciou a conciliação entre Contabilidade Financeira e Gerencial \\
\hline 18 & Evidenciou detalhe por representatividade de clientes \\
\hline 19 & Evidenciou se possui clientes com representatividade maior de 10\% da receita total \\
\hline
\end{tabular}

Fonte: Adaptado de Nyama et al. (2010) e Borba et al. (2009).

No Quadro 1, apresentou-se o modelo utilizado, composto por 19 itens passíveis de análise. Posterior à identificação de cada item passível de disclosure, foi utilizada a matriz de dados para demonstrar a intensidade dos quesitos identificados no processo de análise e conteúdo das notas explicativas, conforme apresenta-se no Quadro 2.

Quadro 2 - Qualidades observadas no nível de disclosure das notas explicativas (2010)

\begin{tabular}{|c|l|}
\hline Intensidade & \multicolumn{1}{c|}{ Abrangência do conteúdo } \\
\hline 0 & Não foi mencionado nas notas explicativas \\
\hline 1 & Foi mencionado nas notas explicativas \\
\hline
\end{tabular}

Fonte: Adaptado de Guthrie et al. (2009).

No estudo de Guthrie et al. (1999), foi utilizado um sistema com quatro códigos numéricos com o intuito de investigar a evidenciação (nos Relatórios de Administração) de aspectos relacionados ao Capital Intelectual. Esse trabalho também foi utilizado por Matos et al. (2008), Ensslin e Carvalho (2007) e depois por Machado et al. (2011). Para o presente estudo, foi utilizado o mesmo critério com adaptações quanto à quantidade de intensidades, além de modificações na sentença, pois se destina a analisar o CPC 22. Após a codificação do

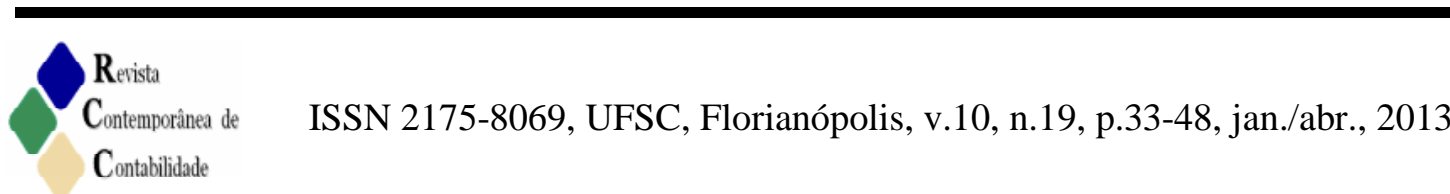


conteúdo das companhias contidas no IBrX-50, analisou-se a base de dados estatisticamente com o apoio do software EViews, versão 7.1.

\subsection{Modelo de Regressão}

Após a Análise de Conteúdo, aplicou-se o modelo de regressão múltipla, sendo que a somatória da pontuação de cada empresa correspondeu à variável dependente do modelo. Os dados adicionais da amostra de 48 empresas, considerados nas variáveis independentes, foram extraídos da Economática. Como o modelo de regressão considerou dados de diversas empresas para um mesmo período, no caso 2010, os dados enquadram-se como dados em corte transversal (GUJARATI, 2006).

A escolha da regressão múltipla para os dados obtidos deve-se por ser uma técnica de dependência confirmatória que tem por objetivo estudar o comportamento de uma variável dependente em função de uma ou mais variáveis explicativas, a fim de que seja analisada (i) a influência relativa de cada uma delas; (ii) a investigação da dependência entre as variáveis; e (iii) a elaboração de previsões (FAVERO et al., 2009). O modelo de regressão corresponde à seguinte equação:

Em que:

$$
\mathrm{Y} 1=\alpha+\beta 1 . \mathrm{X} 1+\beta 2 . \mathrm{X} 2+\beta 3 . \mathrm{X3}+\beta 4 . \mathrm{X} 4+\beta 5 . \mathrm{X} 5+\mathrm{u}
$$

$\boldsymbol{\alpha}=$ Intercepto do modelo (constante).

$\mathbf{Y}_{1}=$ Variável dependente: pontuação resultante da análise de conteúdo.

$\mathbf{X}_{\mathbf{1}}=$ Variável independente: dummy de Novo mercado (empresa está contida=1; empresa não está contida $=0$ ).

$\mathbf{X}_{\mathbf{2}}=$ Variável independente: Valor em reais da Margem Ebitda (Earnings before interest, tax, depreciation and amortization.

$\mathbf{X}_{\mathbf{3}}=$ Variável independente: Valor em reais da Margem Bruta.

$\mathbf{X}_{\mathbf{4}}=$ Variável independente: Valor em reais do Ativo Total (variável de controle).

$\mathbf{X}_{\mathbf{5}}=$ Variável independente: dummy do Lucro Líquido (Valor positivo=1; valor negativo $=0$ ).

$\mathbf{u}=$ Resíduo do modelo.

O resultado esperado da análise do modelo de regressão é compreender: (i) empresas listadas no Novo Mercado evidenciam mais as informações por segmento; (ii) empresas com maiores resultados de Margem Ebitda evidenciam mais as informações por segmento; (iii) empresas com maiores resultados de Margem Bruta evidenciam mais as informações por segmento; (iv) empresas com maiores valores de Ativo Total evidenciam mais as informações por segmento; e, (v) empresas com Lucro Líquido positivo evidenciam mais as informações por segmento.

\section{Apresentação e Discussão dos Resultados}

Para a Análise de Conteúdo verificou-se que 10 empresas não publicaram a Nota Explicativa de Informações por Segmento. Dentre as companhias que não divulgaram essas 
informações, $40 \%$ das empresas não apresentaram justificativas e nem mencionaram qualquer informação por segmento. Das demais empresas que não publicaram a Nota Explicativa, 40\% informaram que possuem apenas um único segmento, e as $20 \%$ restantes não possuem ou não utilizam para a gestão do negócio a informação por segmento. A estatística descritiva referente às empresas analisadas apresenta-se na Tabela 1.

Tabela 1 - Estatística descritiva

\begin{tabular}{l|c|l|c}
\hline \multicolumn{4}{c}{ Resultados Estatísticos Descritivos } \\
\hline Média & $\mathbf{9 , 1 0}$ & Mínimo & $\mathbf{0 , 0 0}$ \\
\hline Erro padrão & $\mathbf{0 , 7 4}$ & Máximo & $\mathbf{1 7 , 0 0}$ \\
\hline Mediana & $\mathbf{1 0 , 5 0}$ & Soma & $\mathbf{4 3 7 , 0 0}$ \\
\hline Desvio padrão & $\mathbf{5 , 1 1}$ & Contagem & $\mathbf{4 8 , 0 0}$ \\
\hline Variância da amostra & $\mathbf{2 6 , 1 0}$ & &
\end{tabular}

Fonte: Dados da pesquisa.

Após a Análise de Conteúdo, a pontuação máxima que cada empresa listada no IBrX50 poderia obter corresponde a 19 pontos. Com base na Tabela 1, verificou-se que a média geral de pontuação das 48 empresas foi 9,1 , enquanto a mediana foi 10,50 . Dentre as empresas, a maior pontuação obtida foi 17 pontos, alcançada por uma empresa do setor de mineração.

A pontuação total correspondente às 48 empresas da amostra foram 437 pontos, enquanto que a métrica poderia atingir 912 pontos. Essa pontuação demonstra o baixo nível de disclosure na amostra analisada, uma vez que representou menos de 50\% do total possível de pontos. As categorias evidenciadas pelas empresas foram agregadas por setor, conforme a Economática, as quais se apresentam na Tabela 2.

Tabela 2 - Ranking por setor - Análise de Conteúdo

\begin{tabular}{c|l|c|c|c}
\hline Ranking & \multicolumn{1}{|c|}{ Setor Economática } & $\begin{array}{c}\text { Quantidade de } \\
\text { Empresas }\end{array}$ & $\begin{array}{c}\text { Análise de } \\
\text { Conteúdo } \\
\text { Pontos }\end{array}$ & $\begin{array}{c}\text { Média do } \\
\text { Setor }\end{array}$ \\
\hline 1 & Mineração & 2 & 30 & 15 \\
\hline 2 & Siderurgia e Metalurgia & 4 & 56 & 14 \\
\hline 3 & Comércio & 4 & 49 & 12 \\
\hline 4 & Finanças e Seguros & 5 & 56 & 11 \\
\hline 5 & Papel e Celulose & 1 & 11 & 11 \\
\hline 6 & Outros & 2 & 21 & 11 \\
\hline 7 & Alimentos e Bebidas & 5 & 52 & 10 \\
\hline 8 & Química & 1 & 9 & 9 \\
\hline 9 & Transporte e Serviços & 4 & 35 & 9 \\
\hline 10 & Construção & 6 & 45 & 8 \\
\hline 11 & Energia Elétrica & 4 & 26 & 7 \\
\hline 12 & Petróleo e Gás & 5 & 25 & 5 \\
\hline 13 & Telecomunicações & 3 & 14 & 5 \\
\hline 14 & Software e Dados & 2 & 8 & 4 \\
\hline
\end{tabular}

Fonte: Dados da pesquisa.

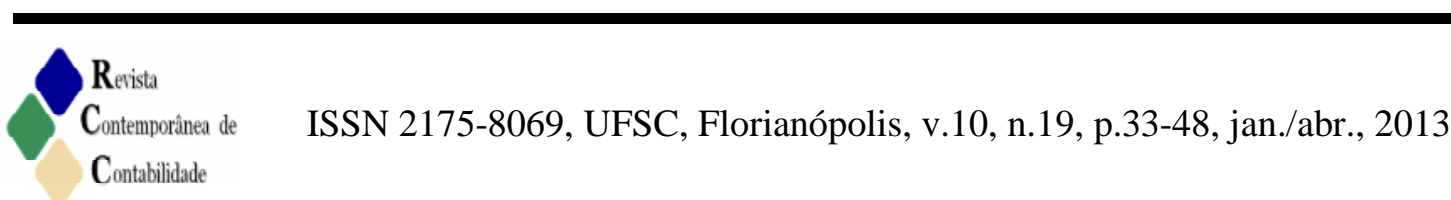


$\mathrm{Na}$ análise dos setores, extraídos da Economática, os que atingiram maior média na pontuação da Análise de Conteúdo foram os setores de Mineração, seguido pelo de Siderurgia e Metalurgia. As empresas que obtiveram pontuação menor ou igual a 1 estão contidas nos seguintes segmentos da Economática: Construção (2), Energia Elétrica (2), Outros (3), Software e Dados (1) e Telecomunicações (2).

As categorias que apresentaram maior evidenciação dentre as empresas que divulgaram a nota explicativa de informações por segmento foram: 2-Evidenciou quem é o principal gestor das operações, apresentada por 40 empresas; seguida pelas categorias 4Evidenciou se foi adotada como unidade de negócio ou região geográfica, 5-Evidenciou a quantidade de segmentos operacionais, 7-Evidenciou base comparativa, essas categorias apresentaram-se em 38 empresas; e evidenciada por 36 empresas apresenta-se a categoria 8Evidenciou Receitas por segmento.

Sobre a categoria 4, que trata sobre a evidenciação por unidade de negócio ou região geográfica, destaca-se que, das 38 empresas, $66 \%$ das empresas divulgaram seus segmentos por linha de atividade ou unidade de negócio; em contrapartida, $26 \%$ divulgaram seus segmentos por região geográfica; e apenas $8 \%$ apresentaram seus segmentos operacionais por unidade de negócio e também por região geográfica. Esses resultados corroboram os achados de Garrod (2005) e Schneider e Scholze (2011), uma vez que a divulgação das informações por região geográfica pode evidenciar informações comerciais estratégicas em relação aos mercados de atuação.

As categorias com menor evidenciação foram: 17 - Evidenciou a conciliação entre a Contabilidade Financeira e a Gerencial; 19 - Evidenciou se possui clientes com representatividade maior de $10 \%$ da receita total, demonstradas em apenas quatro empresas; e 13-Evidenciou Ebitda por segmento; 6-Evidenciou o método de agregação de segmentos, evidenciadas em seis empresas.

Para a análise do modelo de regressão, os testes foram realizados no software Eviews, versão 7.1, com o método Stepwise, pelo procedimento Backwards e p-valor de 5\%. O resumo do output da regressão apresenta-se na Tabela 3.

Tabela 3 - Outputs da Regressão

Dependent Variable: Pontuação na Análise de Conteúdo

Method: Stepwise Regression

Sample: 148

Included observations: 48

\begin{tabular}{lcccr}
\hline \multicolumn{1}{c}{ Variable } & Coefficient & Std. Error & t-Statistic & Prob. \\
\hline LUCROLIQ_DEZ2010_BI & 9.409091 & 0.795793 & 11.82354 & 0.0000 \\
\hline R-squared & -0.067802 & Mean dependent var & 9.104167 \\
Adjusted R-squared & -0.067802 & Durbin-Watson stat & 1.995075 \\
\hline
\end{tabular}

Fonte: Dados da pesquisa.

Dentre as variáveis explicativas inseridas no modelo de regressão, apenas a variável independente dummy do Lucro Líquido se mostrou significativa, ou seja, rejeitou a hipótese nula ao nível de significância de 0,05 . Sugere-se com base nesse resultado que as empresas que apresentam Lucro Líquido positivo tendem a divulgar mais informações por segmento em relação às empresas que apresentam resultados negativos. 
O resultado do modelo não permitiu inferir que as empresas listadas no Novo Mercado evidenciam mais informações por segmento em relação às empresas não listadas nesse nível diferenciado de Governança. Assim, como a Margem Ebitda, Margem Bruta, Ativo Total não foram significantes, ou seja, não influenciaram a divulgação das informações por segmento para a amostra analisada.

Quanto aos pressupostos da regressão, o modelo em análise não apresentou heterocedasticidade, pois pelo teste White a hipótese nula não foi rejeitada ao nível de significância de 0,05 , e os resíduos possuem variância constante ou homogênea em toda a extensão das variáveis independentes.

Tabela 4 - Teste de Heterocedasticidade

\begin{tabular}{llll}
\hline \multicolumn{4}{c}{ Heteroskedasticity Test: White } \\
\hline F-statistic & 3.899346 & Prob. F(11,288) & 0.0543 \\
Obs*R-squared & 3.750923 & Prob. Chi-Square(11) & 0.0528 \\
Scaled explained SS & 3.241898 & Prob. Chi-Square(11) & 0.0718 \\
\hline
\end{tabular}

Fonte: Dados da pesquisa.

Como os dados do presente estudo são classificados como dados em corte transversal, de acordo com Fávero et al. (2009), não há fundamento na aplicação do teste de Durbin Watson para testar o problema de autocorrelação, uma vez que a mudança, na ordem das observações, alterará a estatística $d$, mas não modificará a lógica do modelo proposto. Concordando com Fávero et al. (2009), Gujarati (2006) define autocorrelação como a correlação entre integrantes de séries de observações ordenadas no tempo ou no espaço, ou seja, mais de um ano de análise para amostra em estudo.

Para o pressuposto da Multicolinearidade, por se tratar de uma questão de grau e não de tipo, a distinção não é entre a presença ou a ausência de multicolinearidade, mas, sim, entre os seus graus. Em situações em que a regressão é apenas para previsão ou prognóstico, a existência de multicolinearidade não se torna um problema grave (GUJARATI, 2006). Neste trabalho, o objetivo da regressão foi para o prognóstico das variáveis explicativas sobre a variável dependente, logo não seria considerado um problema grave. Na análise de correlação das variáveis, não foi identificado correlação superior a 0,70 entre as variáveis explicativas do modelo, então não foi detectado a colinearidade.

A análise com base na amostra proposta demonstrou semelhança com os resultados de Benjamin et al. (2010), uma vez que as informações divulgadas são de baixa qualidade em relação à proposta de adoção das normas internacionais. Assim como a insatisfação com a norma, levantada por Gamble e Simms (2010) em relação à discrionaridade dos gestores na divulgação dessas informações, o que restringe análises de longo prazo, principalmente quanto a decisões de investimento nos distintos segmentos operacionais da empresa.

A relação entre divulgação e Lucro Líquido, positivo ou negativo, encontrada neste trabalho demonstrou que empresas com resultados negativos tendem a ocultar informações. Nesse caso, informações por segmento, que podem revelar a estratégia da empresa (MOURAD, 2009) ou a ineficiência de alguns gestores, são inibidas nessa nota explicativa. 


\section{Considerações Finais}

Este estudo teve como objetivo geral verificar como são evidenciadas as informações gerenciais publicadas na nota explicativa de informações por segmento nas empresas que compõem o IBrX-50. Para isso foi utilizada a combinação de Análise de Conteúdo e o Método Stepwise de Regressão Múltipla.

Verificou-se que a evidenciação é distinta entre os diversos setores, destacando-se o setor de Mineração com o maior nível de divulgação, enquanto que o setor de Software e Dados atingiu a menor pontuação para as categorias analisadas. Outros setores como Telecomunicações, e Petróleo e Gás tiveram pouca evidenciação, fato que pode despertar o interesse de novos pesquisadores, pois pode ser explicado pela alta regulação por órgãos públicos ou pela alta competitividade dos segmentos, o que inibe o nível de evidenciação, fato estudado por Garrod (2005).

Ao analisar quais informações gerenciais são mais evidenciadas, verificou-se baixo nível de divulgação por parte das empresas. Em relação à métrica utilizada e às categorias propostas, menos da metade da divulgação, possível de acordo com o modelo proposto, foi evidenciado pelas empresas.

Chama-se atenção para a evidenciação por unidade de negócio ou região geográfica, destacada em muitos estudos como fonte relevante para informação comercial estratégica. No estudo, a maioria das empresas divulgou suas informações por linha de atividade ou unidade de negócio. Sugere-se desse achado que as empresas agregam informações e optam por não divulgar por região geográfica, como uma forma de barreira de entrada e resguardar a divulgação de algumas informações estratégicas da empresa.

Nas informações em que houve menor nível de divulgação pelas empresas, destaca-se a categoria que trata da representatividade de clientes, pois as empresas precisariam divulgar os clientes que possuem mais de $10 \%$ de representatividade da receita total. Infere-se que as empresas podem optar por reter essa informação no intuito de não despertar interesse dos concorrentes pelos seus clientes estratégicos.

Ao verificar quais fatores influenciam a divulgação na nota explica de informações por segmento, não foi possível estabelecer relações com as variáveis Novo Mercado, Margem Ebitda, Margem Bruta, Ativo Total. Esses fatores não permitiram explicar a maior ou menor divulgação das informações por segmento nas notas explicativas.

No modelo testado, apenas a variável Lucro Líquido apresentou significância, ou seja, as empresas que apresentam resultados positivos tendem a divulgar mais informações por segmento em relação às empresas que apresentam resultados negativos.

Os resultados demonstraram que, em relação à evidenciação das informações gerenciais publicadas nas notas explicativas, existe baixo nível de divulgação frente às exigências adotadas a partir da adoção das normas internacionais. Sugere-se ainda que, assim como em outros países, o nível de divulgação não é satisfatório, principalmente no que se refere à discrionaridade dos gestores na divulgação dessas informações, que limita análises de longo prazo e decisões de investimento nos distintos segmentos operacionais da empresa.

Conclui-se que existe uma tendência de ocultar informações nas notas explicativas de informações por segmento, ou seja, suprimi-se a divulgação das informações quando as organizações não apresentam resultados positivos. O que pode ser um indício da tentativa de 
omitir a ineficiência de alguns gestores e adicionalmente como outra possibilidade reside como um entrave de novos competidores no mercado de atuação.

A pesquisa limitou-se à análise dos dados extraídos das notas explicativas e Economática, com base em 2010, pois a exigência da publicação das informações por segmento começou a partir de 2010.

Este estudo contribuiu para a literatura ao abordar o nível de evidenciação das Informações por Segmento, informação recente a qual poderá ser utilizada para diversas decisões: (i) análises de mercado; (ii) de competitividade entre empresas; (iii) análise de alocação de investimentos, principalmente pelos acionistas minoritários, uma vez que o CPC 22 gera uma visão adicional que permite avaliar se as empresas estão investindo nos segmentos operacionais com maior lucratividade ou rentabilidade, a depender da estratégia da empresa. Para futuras pesquisas sugere-se avaliar o impacto de outros fatores no modelo de regressão; expandir o tamanho da amostra para todas as empresas listadas no IBOVESPA; realizar análise de dados em painel com o cruzamento da Análise de Conteúdo de várias empresas e em vários anos a partir das próximas publicações.

\section{Referências}

BARDIN, L. Análise de conteúdo. Lisboa: Edições 70, 1977.

BENJAMIN, S.; MUTHAIYAH, S.; MARATHAMUTHU, M.; MURUGAIAH, U. A study of segment reporting practices: a Malaysian perspective. Journal of Applied Business Research, v. 26, n. 3, 2010.

BIRT, J. L.; BILSON, C. M.; SMITH, T.; WHALEY, R. E. Ownership, competition and financial disclosure. Australian Journal of Management, v. 31, n. 2, p. 235-263, 2006.

BOLSA DE VALORES DE SÃO PAULO (BOVESPA). Consulta classificação setorial. Disponível em: <http://www.bmfbovespa.com.br>. Acesso em 10 junho 2010.

BORBA, J. A.; SOUZA, M. M; ZANDONAI, F. Evidenciação da perda no valor recuperável de ativos nas demonstrações contábeis: uma verificação as empresas de capital aberto brasileiras. In: Encontro da Associação Nacional de Pós-Graduação e Pesquisa em Administração. 33. 2009, São Paulo. Anais... São Paulo: ANPAD, 2009. CD-ROM.

BOSCOV, C. P. O enfoque gerencial na divulgação de informações por segmento. 2009. Dissertação (Mestrado em Controladoria e Contabilidade) - Faculdade de Economia, Administração e Contabilidade da Universidade de São Paulo. São Paulo, 2009.

COMISSÃO DE VALORES MOBILIÁRIOS (CVM). Consulta das notas explicativas das empresas listadas no IBrX - 50. Disponível em: <http://www.cvm.gov.br>. Acesso em 5 julho 2010.

ENSSLIN, S. R.; CARVALHO, F. N.; Voluntary disclosure of intellectual capital in the Brazilian context: an investigation informed by the international context. International Journal of Accounting, Auditing and Performance Evaluation. v. 4, p. 478-500, 2007.

EPSTEIN, B. J.; JERMAKOWICZ, E. K. Interpretation and application of International Financial Reporting Standards. Hoboken: Wiley, 2010. 
FAVERO, L. P.; BELFIORE, P.; DA SILVA, F. L.; CHAN, B. L. Análise de Dados: modelagem multivariada para tomada de decisões. Rio de Janeiro: Elsevier, 2009.

FREITAS, H. M. R.; CUNHA JR, M. V. M.; MOSCAROLA, J. Aplicação de sistema de software para auxílio na análise de conteúdo. Revista de Administração da USP - RAUSP. v. 32, n. 3, p. 97-109, jul./set. 1997.

FREITAS, H. M. R. de; JANISSEK-MUNIZ, R. . Análise Léxica e Análise de Conteúdo: técnicas complementares, sequenciais e recorrentes para análise de dados qualitativos.. 1. ed. Porto Alegre: Sphinx Publicações, 2000. v. 3000. 176 p.

FREZATTI, F.; AGUIAR, A. B.; GUERREIRO, R.. Diferenciações entre a Contabilidade financeira e a Contabilidade gerencial: uma pesquisa empírica a partir de pesquisadores de vários países. Revista de Contabilidade e Finanças - USP, n. 44, p. 9-22, mai/ago, 2007.

GUJARATI, D. N. Econometria Básica. 5. ed. Rio de Janeiro: Elsevier, 2006.

GAMBLE, G.; SIMMS, J. The role of activity-base costing in the development of segmented financial statements: an examination. Journal of Business \& Economics Research, v. 8, n. 2, 2010.

GARROD, N. Competitive Disadvantage and Segmental Disclosure. Department of Accounting and Finance - University of Glasgow - Working Paper, 2005.

GUTHRIE, J.; PETTY, R.; FERRIER, F.; WELLS, R. There is no accounting for intellectual capital in Australia: review of annual reporting practices and internal measurement of intangibles within Australian organization. In: OECD SYMPOSIUM OF MEASURING AND REPORTING INTELLECTUAL CAPITAL, 1999, Amsterdam. Anais... Amsterdam: OCDE, 1999.

HANSEN, D. R.; MOWEN, M. M. Management Accounting (International Edition), 7 ed. Thomson South-Western, 2005.

IUDÍCIBUS, S.; MARTINS, E.; CARVALHO, L. N. Contabilidade: aspectos relevantes da epopeia de sua evolução. Revista de Contabilidade e Finanças - USP, São Paulo, n. 38, p. 7-19, mai/ago. 2005.

KOLBE, R. H.; BURNETT, M. S. Content-analysis research: an examination of applications with directions for improving research reliability and objectivity. Journal of Consumer Research, v. 18, $\mathrm{n}^{\circ}$ 2, p. 243-500, 1991.

LEMES, S.; CARVALHO, L.N. Efeito da convergência das normas contábeis brasileiras para as normas internacionais do IASB. In: Congresso USP de Controladoria e Contabilidade, 4., 2004, São Paulo. Anais... FEA/USP, 2004. CD-ROM.

MACHADO, E. A.; TAKAMATSU, R. T.; LIMA, G. A. S. F. Reações do Mercado de Capitais Brasileiro à Publicação Voluntária dos Demonstrativos Contábeis em Conformidade com os Padrões Internacionais.. In: V Congresso ANPCONT, 2011, Vitória-ES. Anais... V Congresso ANPCONT, 2011.

MATOS, B.; ENSSLIN, S. R.; REINA, D.; REINA, D. R. M. A evidenciação voluntária do capital intelectual de natureza social e ambiental da empresa Natura Cosméticos S.A. no período de 2003 a 2007. In: Congresso USP de Controladoria e Contabilidade, 9., 2009, São Paulo. Anais... FEA/USP, 2009. CD-ROM. 
MARTINS, G. A. Manual para elaboração de monografias e dissertações. São Paulo: Atlas, 2002.

MARTINS, G. A.; THEÓPHILO, C. R. Metodologia da investigação científica para ciências sociais aplicadas. São Paulo: Atlas, 2007.

MOURAD, N. A. IFRS8: segmentos operacionais: Contabilidade internacional: International Financial Reporting Standards - IFRS. São Paulo: Atlas, 2009.

NIYAMA, J. K.; ONO, H. M.; RODRIGUES, J. M. Disclosure sobre impairment: uma análise comparativa das companhias abertas brasileiras em 2008. Revista de Contabilidade do Mestrado em Ciências Contábeis da UERJ, v. 15, n. 1, p. 67-87, jan./abr., 2010.

PORTER, M. E. Competitive advantage: creating and sustaining superior performance. New York: Free Press, 1985.

RAHAHLEH M. Y. Applying IFRS 8 operating segments in the context of segments reporting in Jordan. The Business Review, Cambridge, v. 16, n² 2, p. 67-90, dec. 2010.

RODRIGUES, J. M.; MACHADO, D. G.; CRUZ, A. P. C. da. Evidenciação de custos ambientais em empresas do segmento de adubos e fertilizantes. Revista Contemporânea de Contabilidade. UFSC, Florianópolis, v. 8, n. 15, p. 63-86, jan./jun., 2011.

SCHNEIDER, G.; SCHOLZE A. Segment Disclosure under the Management Approach: The Impact of Proprietary Costs on Internal Reporting Decisions, 2011. Disponível em: <http://papers.ssrn.com/sol3/papers.cfm?abstract_id=1830264>. Acesso em: 01 jan. 2012.

SOLOMON, J.; SOLOMON A. Private social, ethical and environmental disclosure. Accounting, Auditing \& Accountability Journal, v. 19, n 4, p. 564-591, 2004.

WENCHAO K.; SIMON H. Predictive gains to segmental disclosure matrices, geographic information and industry sector comparability. The British Accounting Review, v. 39, $\mathrm{n}^{\circ} 3$, p. 183-195, sep. 2007. 